\title{
Contrasting Immunohistochemical Localizations in Rat Brain of Two Novel K+ Channels of the Shab Subfamily
}

\author{
Paul M. Hwang, ${ }^{1}$ Majid Fotuhi, ${ }^{1}$ David S. Bredt, ${ }^{1}$ Anne M. Cunningham, ${ }^{2}$ and Solomon H. Snyder \\ 'Departments of Neuroscience, Pharmacology and Molecular Sciences, and Psychiatry, and ${ }^{2}$ Department of Molecular \\ Biology and Genetics, The Johns Hopkins University School of Medicine, Baltimore, Maryland 21205
}

\begin{abstract}
We have localized CDRK and DRK1, two novel $\mathrm{K}^{+}$channels of the Shab subfamily by immunohistochemistry. The two channels are closely related in structure with about $90 \%$ amino acid identity in the $\mathrm{N}$-terminal and middle portions and $60 \%$ identity in the $\mathrm{C}$-terminal region. We observe striking differences in cellular localizations of the two channels. DRK1 tends to localize to cell bodies and proximal dendrites discretely, while CDRK is diffusely present in cell bodies and is also found on fibers in specific brain areas. In the cerebral cortex DRK1 is localized to pyramidal cells, whereas CDRK occurs in small cells, presumably interneurons. These localizations may reflect specialized delayed rectifier functions and targeting properties manifested differentially by $\mathbf{K}^{+}$channel subfamily members.
\end{abstract}

[Key words: Shaker, Purkinje cells, hippocampus, granule cells, subcellular distribution, pyramidal neurons, targeting]

An understanding of $\mathrm{K}^{+}$channel function has been facilitated by the molecular cloning of four members of the $\mathrm{K}^{+}$channel family, Shaker, Shaw, Shal, and Shab (Tempel et al., 1987; Butler et al., 1989), with mammalian homologs identified for all four (Baumann et al., 1988; Tempel et al., 1988; Frech et al., 1989; McKinnon, 1989; Stühmer et al., 1989; Yokoyama et al., 1989; McCormack et al., 1990; Baldwin et al., 1991; Pak et al., 1991a,b; Roberds and Tamkun, 1991). In Drosophila, subtypes of these channels are derived by alternative splicing (Schwartz et al., 1988), while mainly distinct genes give rise to subtypes of mammalian $\mathrm{K}^{+}$channels. Other mammalian $\mathrm{K}^{+}$ channels do not appear to belong to the four main subfamilies (Takumi et al., 1988; Drewe et al., 1992). Although the channels can be differentiated into delayed rectifier as opposed to fast inactivating types, the differential functions of the large diversity of mammalian $\mathrm{K}^{+}$channels are unclear.

Recently we described the molecular cloning of a novel mam-

\footnotetext{
Received Apr. 14, 1992; revised Oct. 10, 1992; accepted Oct. 19, 1992.

This work is supported by U.S. Public Health Service Grant MH-18501, Research Scientist Award DA-00074 to S.H.S., and Training Grant GM-07309 to P.M.H. and D.S.B., and by an FCAR grant of Quebec to M.F., a grant from International Flavors and Fragrances, a grant to A.M.C. from the Medical Foundation, the University of Sydney, and a gift from Bristol-Myers-Squibb. We are especially thankful to C. Blackstone for advice in designing synthetic peptides and in producing antibodies. We are also thankful to K.-W. Yau, R. Huganir, and T.M. Dawson for helpful discussions and C. Waldron and C. Riley for the synthesis of peptides.

Correspondence should be addressed to Solomon H. Snyder, Dept. of Neuroscience, The Johns Hopkins University School of Medicine, 725 N. Wolfe Street, Baltimore, MD 21205.
}

Copyright (C) 1993 Society for Neuroscience $0270-6474 / 93 / 131569-08 \$ 05.00 / 0$ malian member of the Shab subfamily designated CDRK(Hwang et al., 1992) and contrasted its properties with the only mammalian Shab channel previously characterized, DRK1 (Frech et al., 1989). mRNA localizations for these two channels are differentially distributed throughout the brain. In peripheral tissues, notable differences in mRNA levels are apparent for the two channels (Hwang et al., 1992). To examine with higher resolution the differences between these $\mathrm{K}^{+}$channels, we have conducted immunohistochemical analysis and report striking differences in patterns of localization of CDRK and DRK 1 channel proteins not apparent for their mRNA analyzed by in situ hybridization techniques.

\section{Materials and Methods}

The Vectastain immunohistochemistry kit was from Vector. All other materials were purchased from Sigma (St. Louis, MO) unless otherwise specified.

Preparation of antibodies. Synthetic peptides were made as follows: CDRK, amino acids 774-788 (Hwang et al., 1992); and DRK1, amino acids 839-853 (Frech et al., 1989). The synthetic peptides were conjugated to bovine thyroglobin using glutaraldehyde as described (Harlow and Lane, 1988). Antibodies were raised in rabbits using routine immunization protocols boosting and bleeding every 4 weeks (Hazelton Research Products Inc., Denver, PA). Antisera were affinity-purified on columns prepared by conjugating the specific synthetic peptide to BSA (Sigma) via glutaraldehyde and then coupling to Affi-Gel 15 (Bio-Rad) (Harlow and Lane, 1988).

Western analysis. Rats were decapitated and the different brain regions rapidly homogenized (Polytron) in $50 \mathrm{mM}$ Tris $\cdot \mathrm{HCl}(\mathrm{pH} 7.4)$ containing $1 \mathrm{~mm}$ EDTA, $0.5 \mathrm{~mm}$ phenylmethylsulfonyl fluoride, and $1 \mathrm{~mm}$ benzamidine. Samples $(50 \mu \mathrm{g})$ of protein of the different brain regions were electrophoresed on a $7.5 \%$ polyacrylamide gel using the SDS-PAGE system (Laemmli, 1970). Proteins were transferred to Immobilon-P membranes (Millipore) according to Towbin et al. (1979). The blots were blocked with $3 \%$ BSA in PBS, incubated with affinity-purified antibody (1:100 dilution), washed, and followed by alkaline phosphatase-linked goat anti-rabbit secondary antibody (1:2000; BoehringerMannheim). These were then washed and the protein bands were visualized in the developer [ $50 \mathrm{~mm}$ Tris $\cdot \mathrm{HCl}, \mathrm{pH} 9.5,100 \mathrm{~mm} \mathrm{NaCl}, 10$ $\mathrm{mM} \mathrm{MgCl} 2,15 \mathrm{mg}$ 5-bromo-4-chloro-3-indolyl phosphate (BoehringerMannheim), and $30 \mathrm{mg}$ nitroblue tetrazolium (Sigma) per $100 \mathrm{ml}$ developer]. For preadsorption experiments, antibodies were preincubated with excess specific peptide antigen for $48 \mathrm{hr}$ at $4^{\circ} \mathrm{C}$.

Immunohistochemistry. Adult male Sprague-Dawley rats were perfused with $3 \%$ freshly depolymerized paraformaldehyde in PBS. Brains were removed and postfixed for $2 \mathrm{hr}$ in $3 \%$ paraformaldehyde followed by cryoprotection in $20 \%$ glycerol. Sections $(40 \mu \mathrm{m}$ ) were cut on a sliding microtome and immediately transferred to $50 \mathrm{~mm}$ Tris $\cdot \mathbf{H C l}$-buffered saline (TBS).

All of the following steps for immunohistochemistry were carried out in TBS. Adjacent sections were permeabilized in $0.04 \%$ Triton X-100 for $30 \mathrm{~min}$, blocked in 10\% normal goat serum for $1 \mathrm{hr}$, and incubated with affinity-purified antiserum solutions for CDRK (1:250) or DRK1 $(1: 250)$ overnight at $4^{\circ} \mathrm{C}$. Horseradish peroxidase staining was done using an avidin-biotin (ABC) kit (Vector). 


\section{A anti-CDRK \\ $\overline{\text { PA TH ST HP CX }}$}

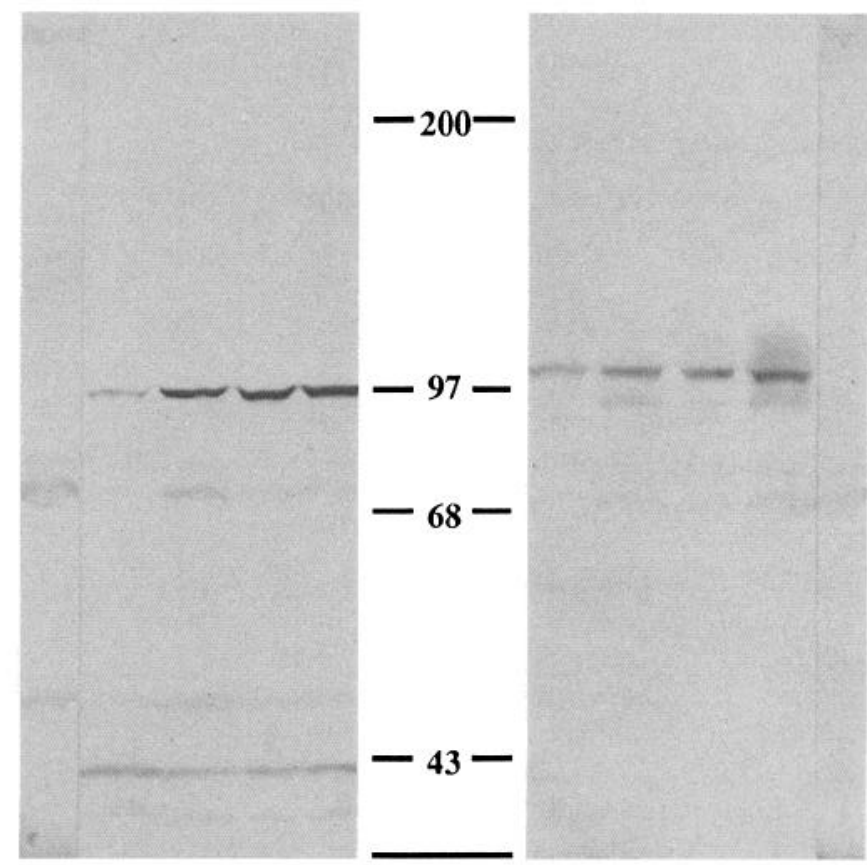

Figure 1. Western analysis of CDRK and DRK1 protein distributions in rat brain. Protein samples $(50 \mu \mathrm{g})$ from the rat thalamus $(T H)$, striatum $(S T)$, hippocampus $(H P)$, and cerebral cortex $(C X)$ were probed with affinity-purified $\mathrm{K}^{+}$channel antibodies. Anti-CDRK antibody $(A)$ recognizes two specific bands at 97 and $42 \mathrm{kDa}$, as determined by comparing with an identically run cerebral cortex sample incubated with preadsorbed affinity-purified antibody $(P A)$. Anti-DRK1 antibody $(B)$ also specifically recognizes two bands at 105 and $95 \mathrm{kDa}$. These bands are abolished by preincubating the affinity-purified DRK 1 antibody with excess DRK1 synthetic peptide ( $P A$, identically run cerebral cortex sample lane).

\section{Results}

\section{Western blot analysis of CDRK and DRK1 protein}

To produce specific antibodies against CDRK or DRK1, we synthesized peptides to portions of the channel proteins that had completely distinct sequences. Since the N-terminal cytoplasmic domain and the transmembrane domains of the two channels show about $90 \%$ amino acid identity, the peptides were synthesized from the C-terminal portion that shows the least similarity. Western blots with the anti-CDRK antiserum in four rat brain regions reveal a prominent band at $97 \mathrm{kDa}$ along with several other bands of lower molecular weight (Fig. 1A). The only bands eliminated by preadsorption of the antibody with the synthetic peptide antigen are the $97 \mathrm{kDa}$ band and a $42 \mathrm{kDa}$ band (Fig. 1 $A$ ).

High densities of the $97 \mathrm{kDa}$ band are evident in cerebral cortex, hippocampus, and corpus striatum with a somewhat lower density in the thalamus. By contrast, the four areas display similar levels of the $42 \mathrm{kDa}$ band, with the highest level in the thalamus in this particular Western blot. In other Western blots using different thalamic membrane preparations, we have observed ratios of the $42 \mathrm{kDa}$ to $97 \mathrm{kDa}$ band similar to other brain regions. Based on amino sequence, the predicted molecular weight of CDRK is $91 \mathrm{kDa}$. It is possible that the $42 \mathrm{kDa}$ band may be a proteolytic CDRK fragment from the C-terminus, as it is specifically eliminated by preadsorbing the antiserum with excess 15 -mer synthetic CDRK peptide. The other possibility is that the $42 \mathrm{kDa}$ peptide is a cross-reacting protein unrelated to CDRK. Arguing for the latter possibility is the observation that the amount of $42 \mathrm{kDa}$ is similar even when we include protease inhibitors in preparing the brain membranes.

Western blot analysis of DRK1 in the same brain regions reveals prominent bands at 105 and $95 \mathrm{kDa}$ and some broad immunoreactivity extending up to $120 \mathrm{kDa}$ (in the cerebral cortex sample) that are eliminated by preadsorption with DRK1 synthetic peptide antigen. Lighter-staining bands at lower molecular weights are not eliminated by such preadsorption. The $95 \mathrm{kDa}$ band is most prominent in the cerebral cortex, somewhat less prominent in the corpus striatum, still lower in the hippocampus, and not evident in the thalamus. The $105 \mathrm{kDa}$ band is evident in all four brain regions, with the lowest amount in the thalamus. The predicted molecular weight of DRK1 is 95 $\mathrm{kDa}$, suggesting that the $105 \mathrm{kDa}$ band may include glycosylated or other constituents, or may migrate aberrantly due to other posttranslational modification.

Trimmer (1991) also raised antibodies against synthetic peptides from DRK1 and conducted immunochemical analyses. One of his DRK1 peptides of 17 amino acids contained sequences identical to ours (839-853). The other peptide used by Trimmer (1991) was from amino acids 516-533, a sequence in which 9 of 18 amino acids of DRK1 are identical to CDRK (Hwang et al., 1992). Similar to our analysis, Trimmer's Western blot of rat brain tissue also revealed staining of a broad band although it was running at about $130 \mathrm{kDa}$. The reasons for the difference in apparent molecular weight from our studies are not clear but may relate to varying experimental conditions. Generally, however, both Trimmer's results and ours reflect significant heterogeneity in the size of DRK1-immunoreactive bands on Western blots.

\section{Immunohistochemical localization of CDRK and DRK1}

Low-power sagittal and coronal sections reveal some global similarities but certain striking regional differences for both CDRK and DRK1 localizations (Figs. 2, 3). Immunoreactivity was completely eliminated by the preadsorption of antisera with their respective synthetic peptides. Highest levels of immunoreactivity are evident in the cerebellum and olfactory bulb, corresponding to the two areas of greatest density of mRNA for both CDRK and DRK1 in our in situ hybridization studies (Hwang et al., 1992). Even at this low-power magnification, certain notable differences are evident between the two channels. In the cerebral cortex, DRK1 labeling is punctate and is found in association primarily with cell bodies, while CDRK is more diffuse, resembling the distribution of neuropil. In the hippocampal formation, a marked, diffuse density of CDRK immunoreactivity is present in the dentate gyrus, fitting with fiber localizations, and this is not evident for DRK1 (Fig. 2). Whereas the molecular layer of the dentate gyrus is most prominently labeled with CDRK, the granule cell layer of the dentate gyrus is more prominently labeled for DRK1, as are the pyramidal cells of CA3 and CA1.

In the olfactory bulb, intense immunoreactivity for both CDRK and DRK1 is evident in granule cells. The olfactory tubercle, immediately adjacent to the olfactory bulb, displays 


\section{A.CDRK}

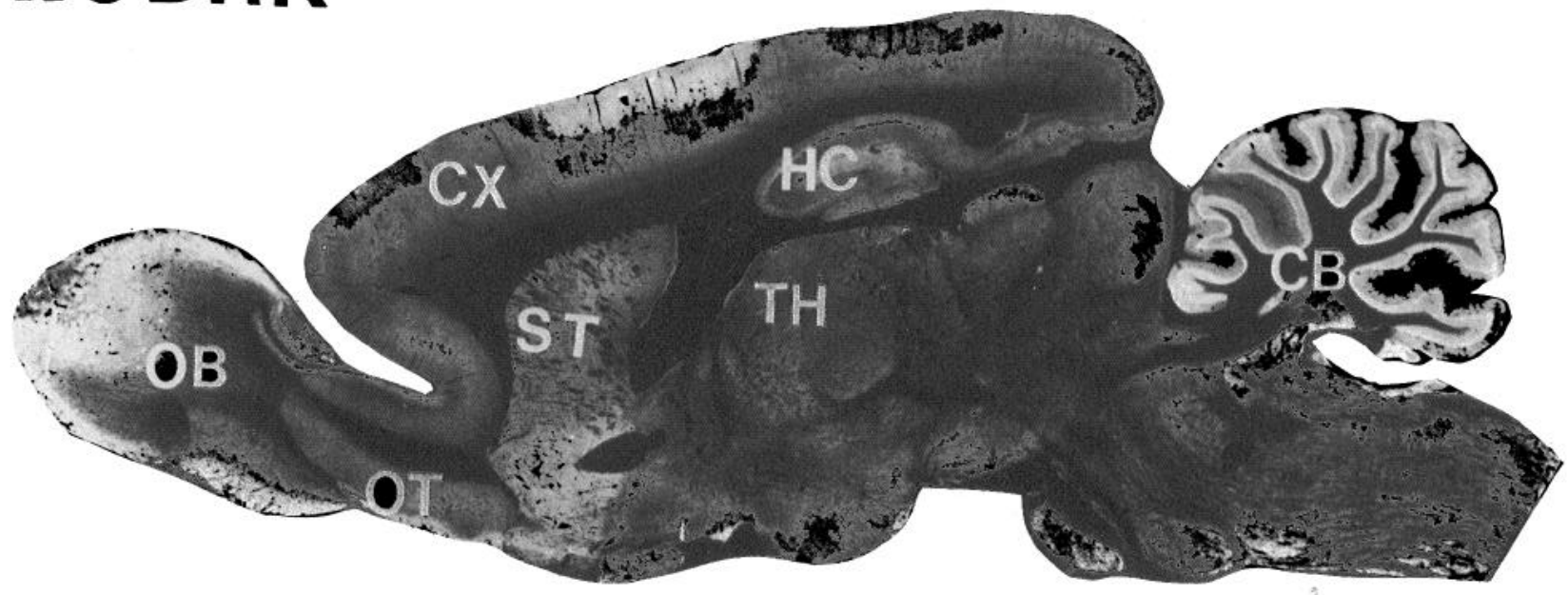

\section{B.DRK1}

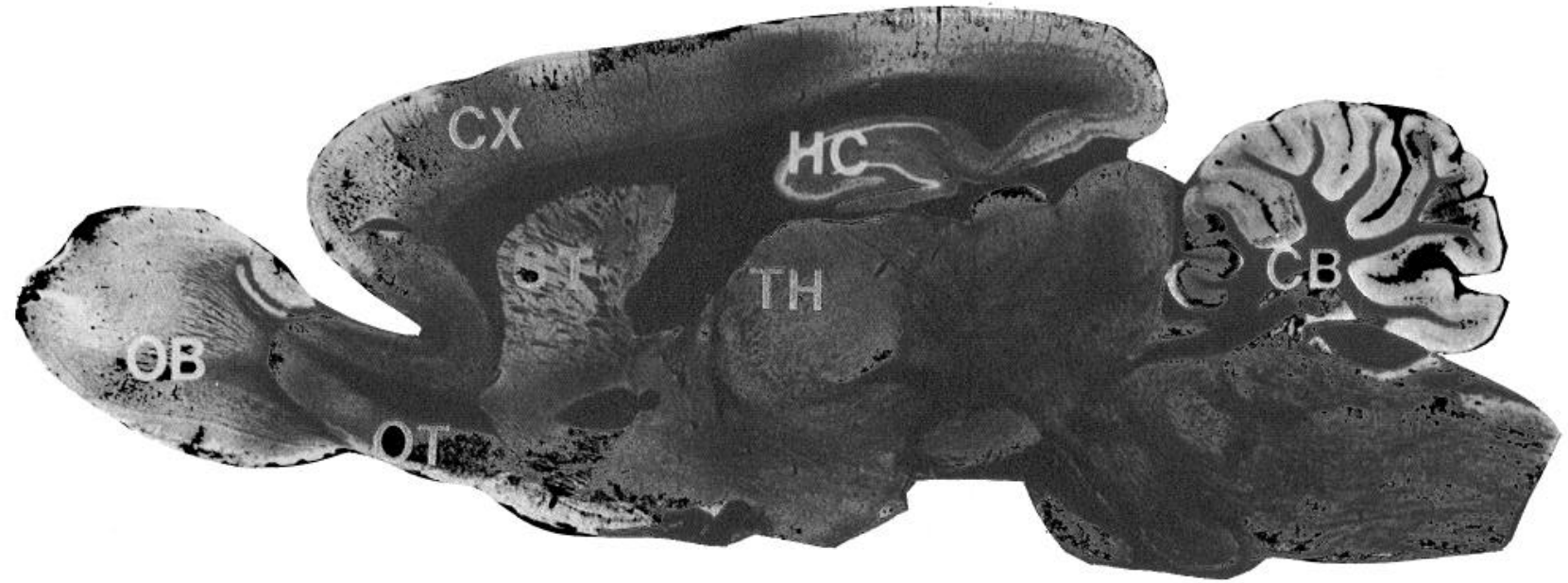

\section{C.CTL}

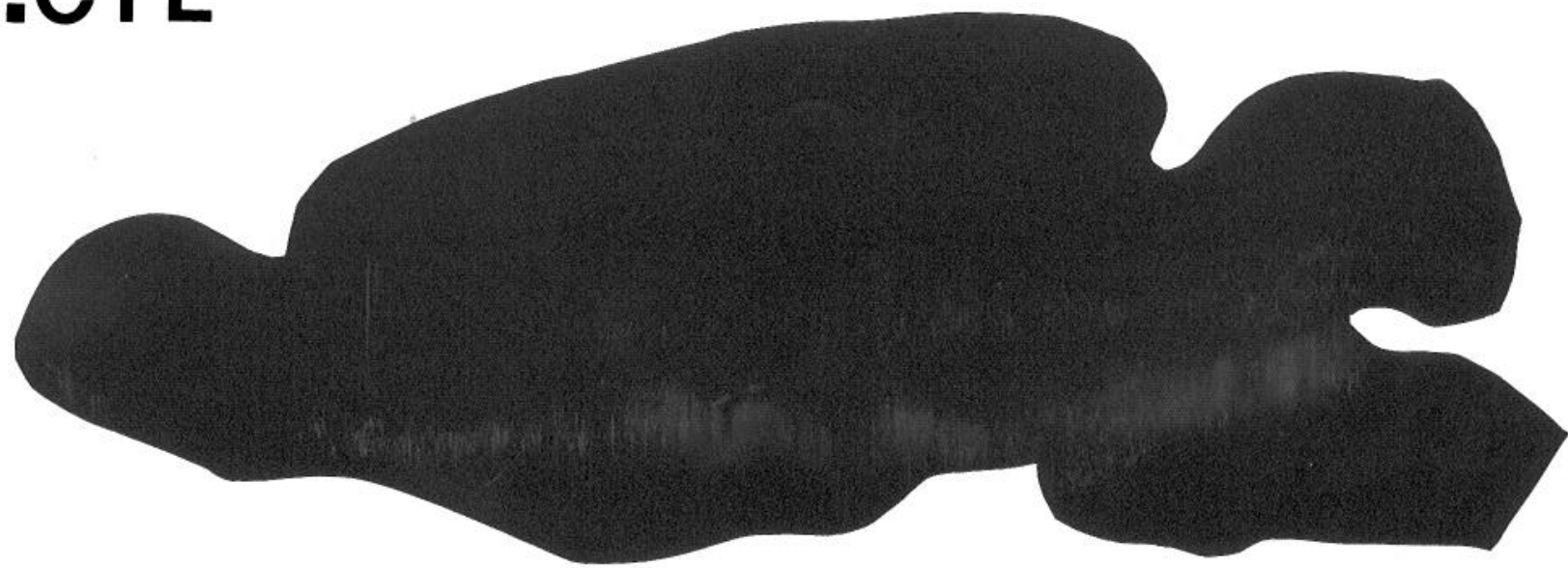

Figure 2. Localizations of CDRK and DRK1 in sagittal brain sections. Thick sections of rat brain were processed for CDRK $(A)$ and DRK1 $(B)$ immunohistochemistry. Preadsorption of antiserum with CDRK peptide completely abolishes immunoreactivity $(C)$; similar preadsorption of the DRK1 antisera with DRK1 peptide abolished immunoreactivity (data not shown). Immunoreactive structures appear white in these dark-field images. Labeled structures are described in Results. $O B$, olfactory bulb; $C X$, cerebral cortex; $O T$, olfactory tubercle; $S T$, striatum; $H C$, hippocampus; $T H$, thalamus; $C B$, cerebellum. 

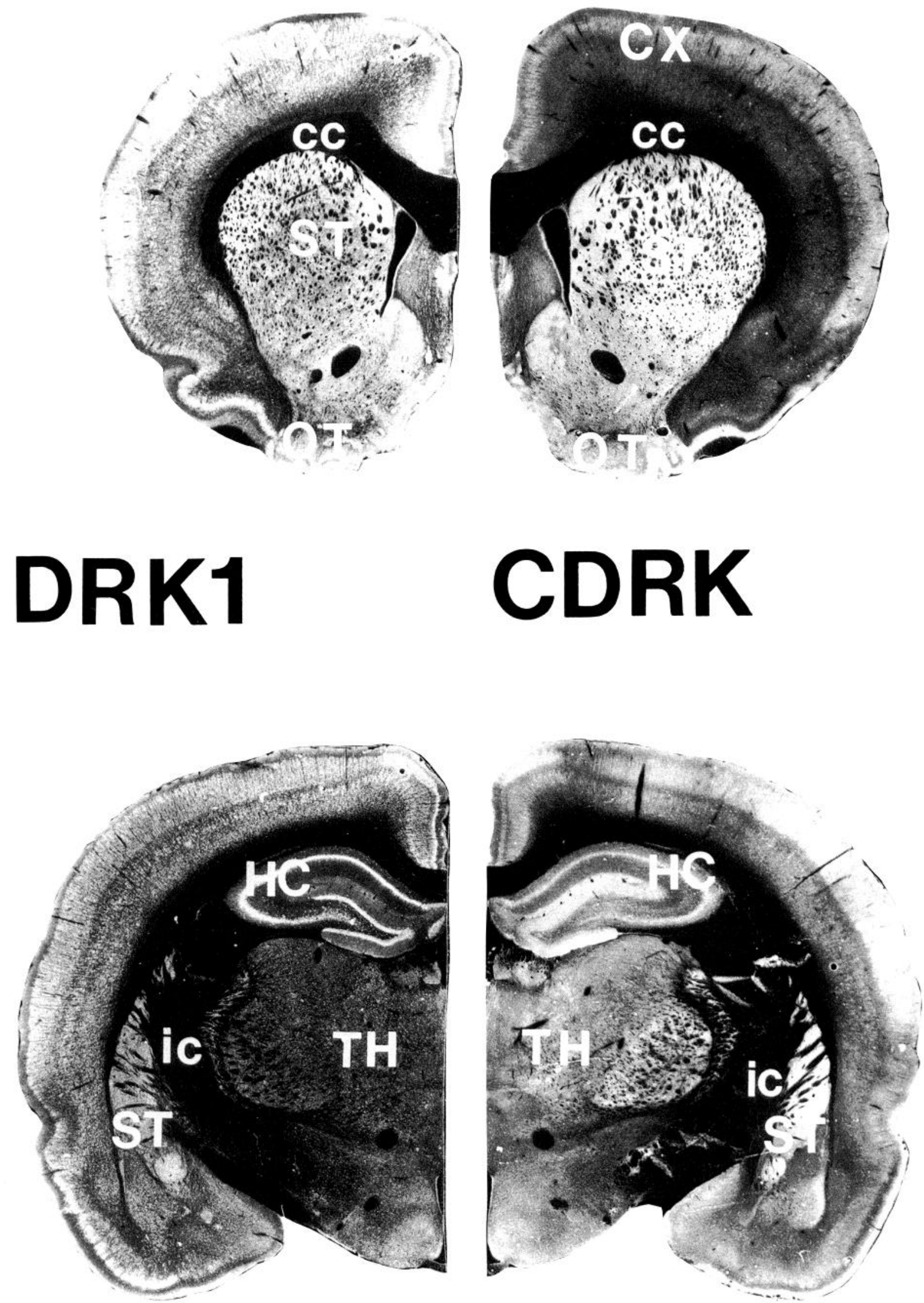

Figure 3. Localizations of DRK1 and CDRK in coronal brain sections. In these dark-field images, immunoreactive structures appear white. The black areas reveal lack of staining. DRK1 (left half) and CDRK (right half) are intensely localized to areas rich in neuronal populations and are not evident in glial-rich white matter areas such as corpus callosum $(c c)$ and internal capsule $(i c) . C X$, cortex; $S T$, striatum; $O T$, olfactory tubercle; $H C$, hippocampus; $T H$, thalamus. 


\section{DRK1}

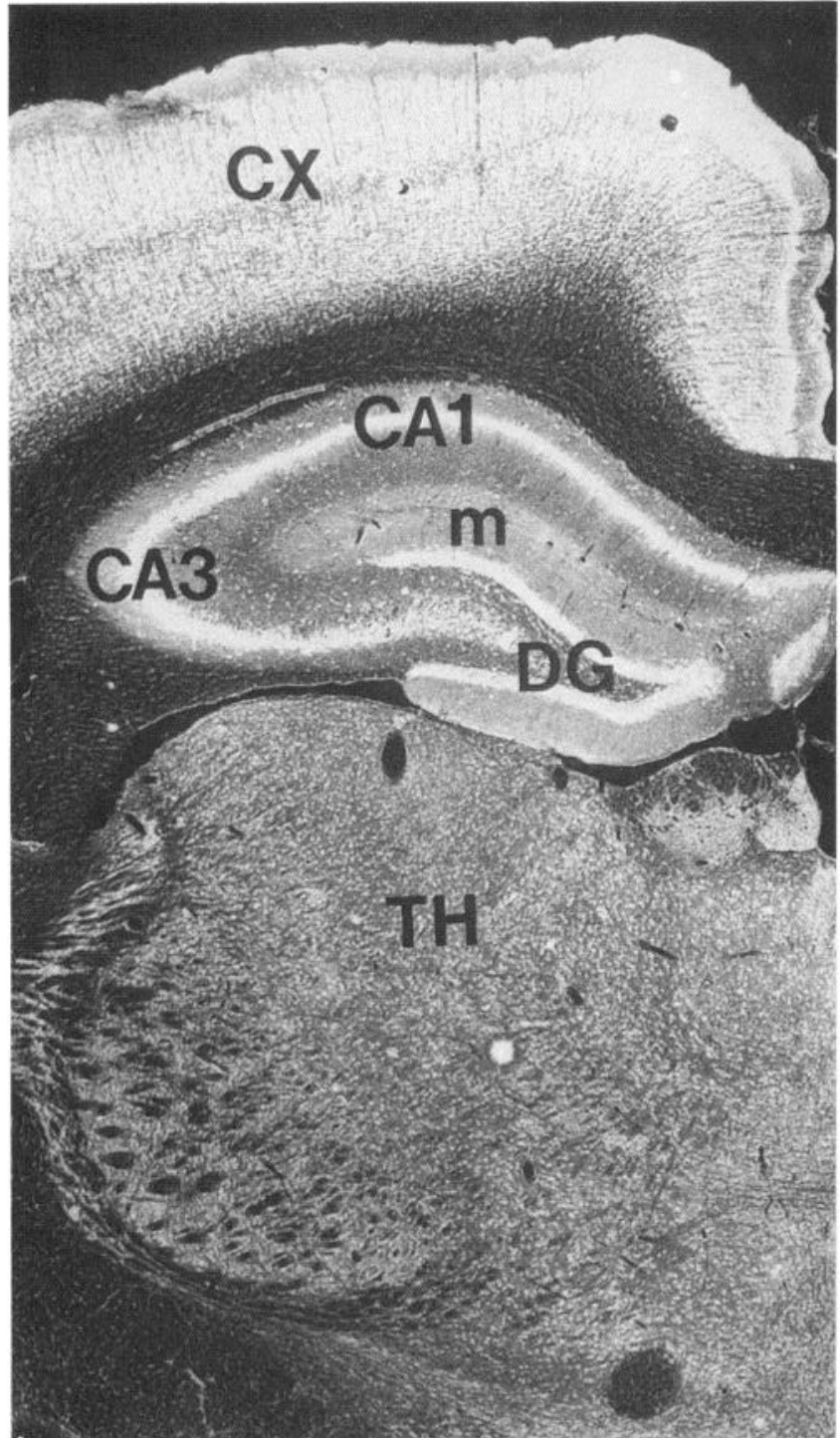

\section{CDRK}

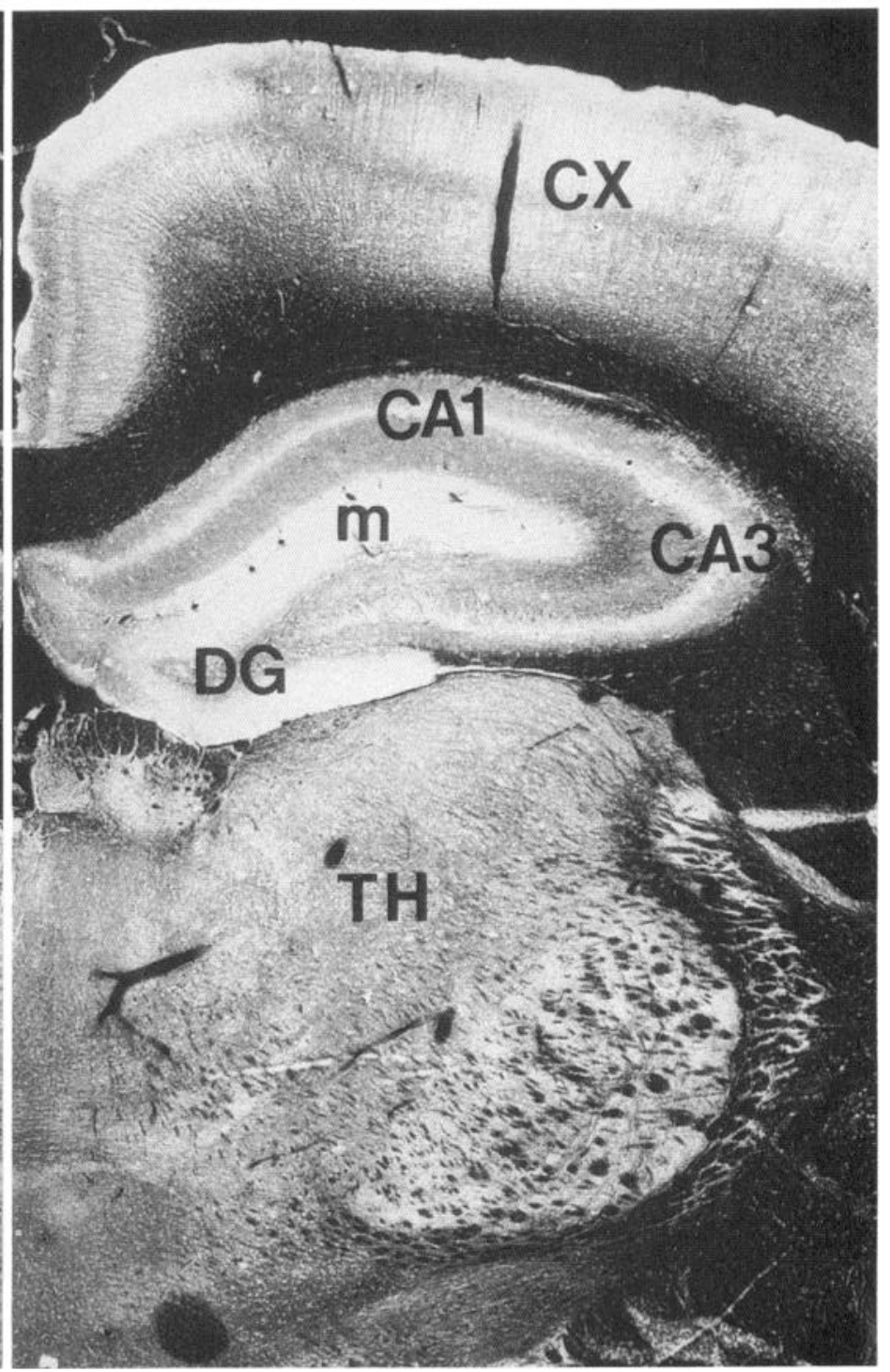

Figure 4. Differential localizations of DRK1 and CDRK in coronal brain sections. This higher magnification of Figure 3 highlights the differential localizations of DRK1 (left half) versus CDRK (right half) in the hippocampus as well as the cerebral cortex $(C X)$ and thalamus (TH). The DRK1 immunoreactivity appears punctate and is predominantly localized to neuronal cell bodies. In contrast, CDRK immunoreactivity appears diffuse and predominates in the neuropil. $D G$, dentate gyrus; $m$, molecular layer of the DG; $C A 1$ and $C A 3$, hippocampal pyramidal cell layers.

substantial immunoreactivity for both channels, with a more discrete pattern for CDRK.

In the cerebellum, both Purkinje cells and granule cells are immunoreactive for the two channels. Overall, levels of immunoreactivity in the molecular and granule cell layers are similar for DRK1, while CDRK immunoreactivity is more intense in the granule cell layer.

At higher magnification, differences between CDRK and DRK1 are even more striking (Figs. 4, 5). Pyramidal cells express immunoreactivity for both channels with a similar intensity in CA1 and CA3 (Fig. 4). In the dentate gyrus the intense DRK1 immunoreactivity of the granule cell layer stands out in contrast to much lower labeling density in the molecular layer. By contrast, the molecular layer of the dentate gyrus expresses intense CDRK immunoreactivity, such that one cannot readily detect the lesser levels of immunoreactivity in the granule cell layer.

In the cerebral cortex at low magnification, the pattern of DRK1 and CDRK immunoreactivity seems similar. However, at higher magnification in bright field they differ markedly (Fig. 5). For DRK1, pyramidal cells are predominantly labeled, with the immunoreactivity most intense in layers II, III, V, and VI. Much less labeling is evident for small neurons than for pyramidal cells. The immunoreactivity of pyramidal cells is extranuclear in the somata and extends throughout the dendritic processes. Although there is substantial diffuse immunoreactivity in the cytoplasm of the pyramidal cells, where presumably the $\mathrm{K}^{+}$channel is synthesized in the endoplasmic reticulum and processed before being transported to the plasma membrane, much of the immunoreactivity is in the punctate synaptic bou- 


\section{DRK1}
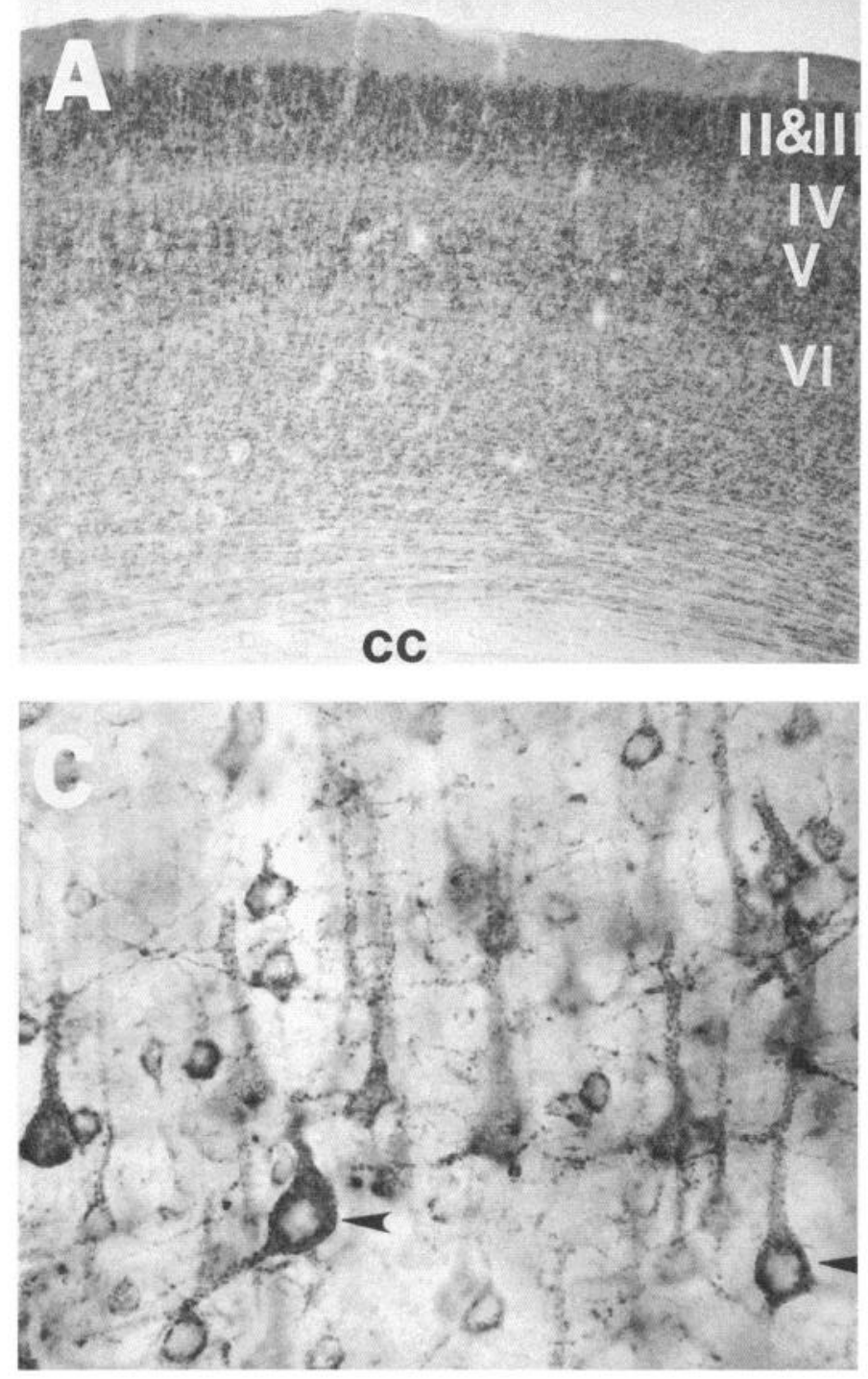

\section{CDRK}
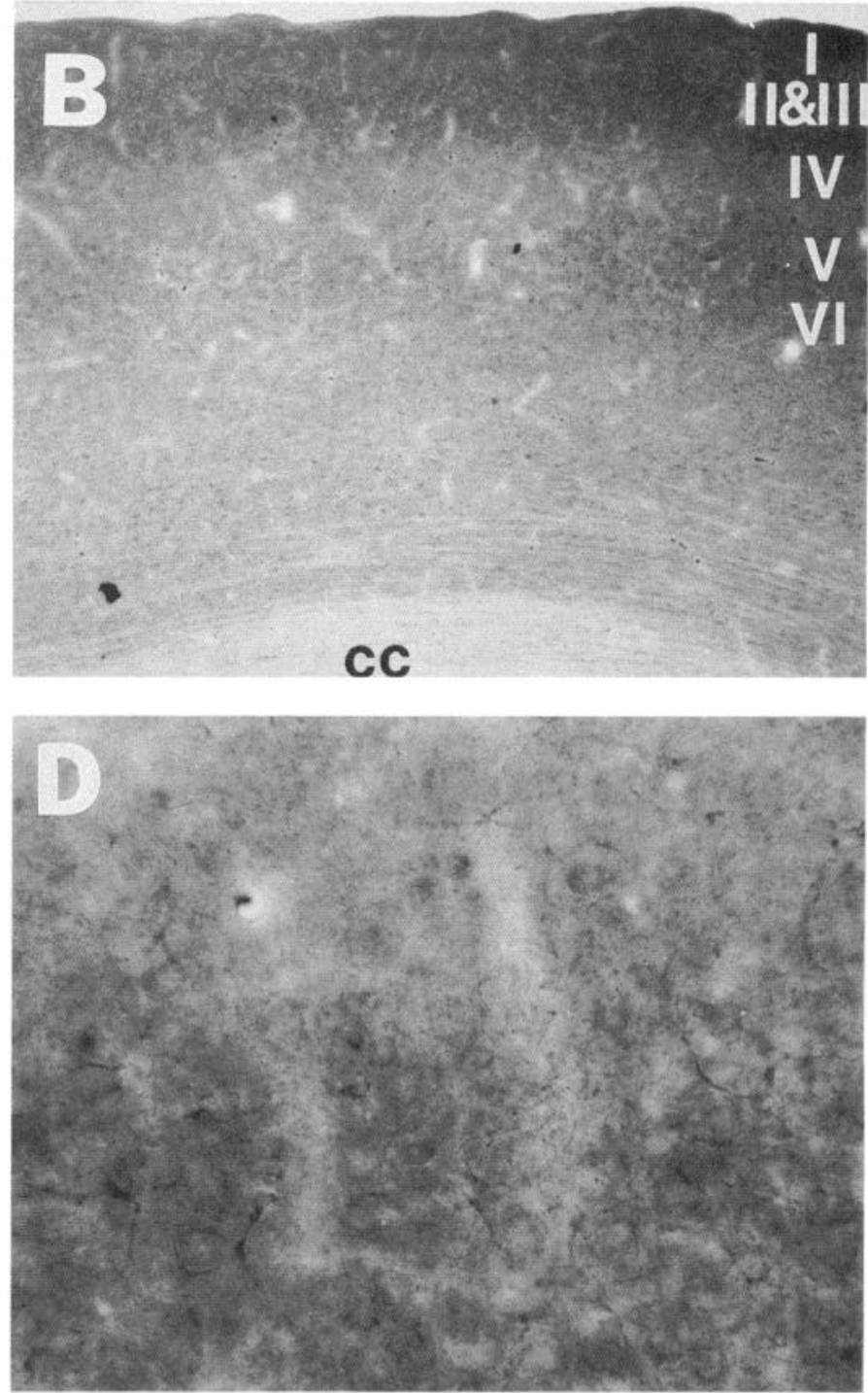

Figure 5. Cellular localizations of DRK1 and CDRK in the cerebral cortex. The bright-field photomicrographs of DRK1 $(A, 60 \times ; C, 500 \times)$ and CDRK $(B, 60 \times ; D, 500 \times)$ show immunoreactivity in different layers and cell populations. DRK1 is predominantly localized to pyramidal cells $(C$, arrowheads) and their dendrites, while CDRK is mainly found in nonpyramidal cells and is diffusely distributed in the neuropil. $c c$, corpus callosum.

tons overlying the cytoplasm of the somatodendritic regions. By contrast, CDRK is readily evident not in pyramidal cells but in smaller nonpyramidal cells with abundant neuropil.

At higher magnification in the cerebellum, Purkinje cells clearly coexpress CDRK and DRK1 (Fig. 6). However, there is a striking difference in patterns of immunoreactivity for the two $\mathrm{K}^{+}$ channels in Purkinje cells. CDRK immunoreactivity is present diffusely over the soma, which would be consistent with a localization either on the plasma membrane or diffusely within the cell body, or both. The dendritic tree of the Purkinje cells is very lightly immunoreactive in the molecular layer. In contrast, DRK1 immunoreactivity is evident in a discrete punctate pattern within Purkinje cell bodies with nuclear clearing, consistent with localization of the $\mathrm{K}^{+}$channel to intracellular processing centers and/or synaptic boutons (Fig. $6 B, D$ ). This punc- tate immunoreactivity for DRK1 extends into the proximal portions of Purkinje cell dendrites (Fig. 6B). This pattern of immunoreactivity is similar to that expressed by the cerebral cortical pyramidal cells (Fig. 5C). DRK1 antibodies also label small cells throughout the molecular layer, consistent with stellate and basket cells (Fig. $6 B$ ).

In the granule cell layer, both CDRK and DRK1 are also present. It is apparent at high magnification that the pattern of CDRK immunoreactivity is diffuse over the cell bodies of granule cells, while the pattern of DRK1 immunoreactivity is one of dense, particulate accumulations associated with the margins of granule cell bodies, localized to one pole of the cell, rather than homogeneously outlining the cell (Fig. 6D). Such a pattern would be consistent with localization to the perikaryal-dendritic region of the granule cells. 

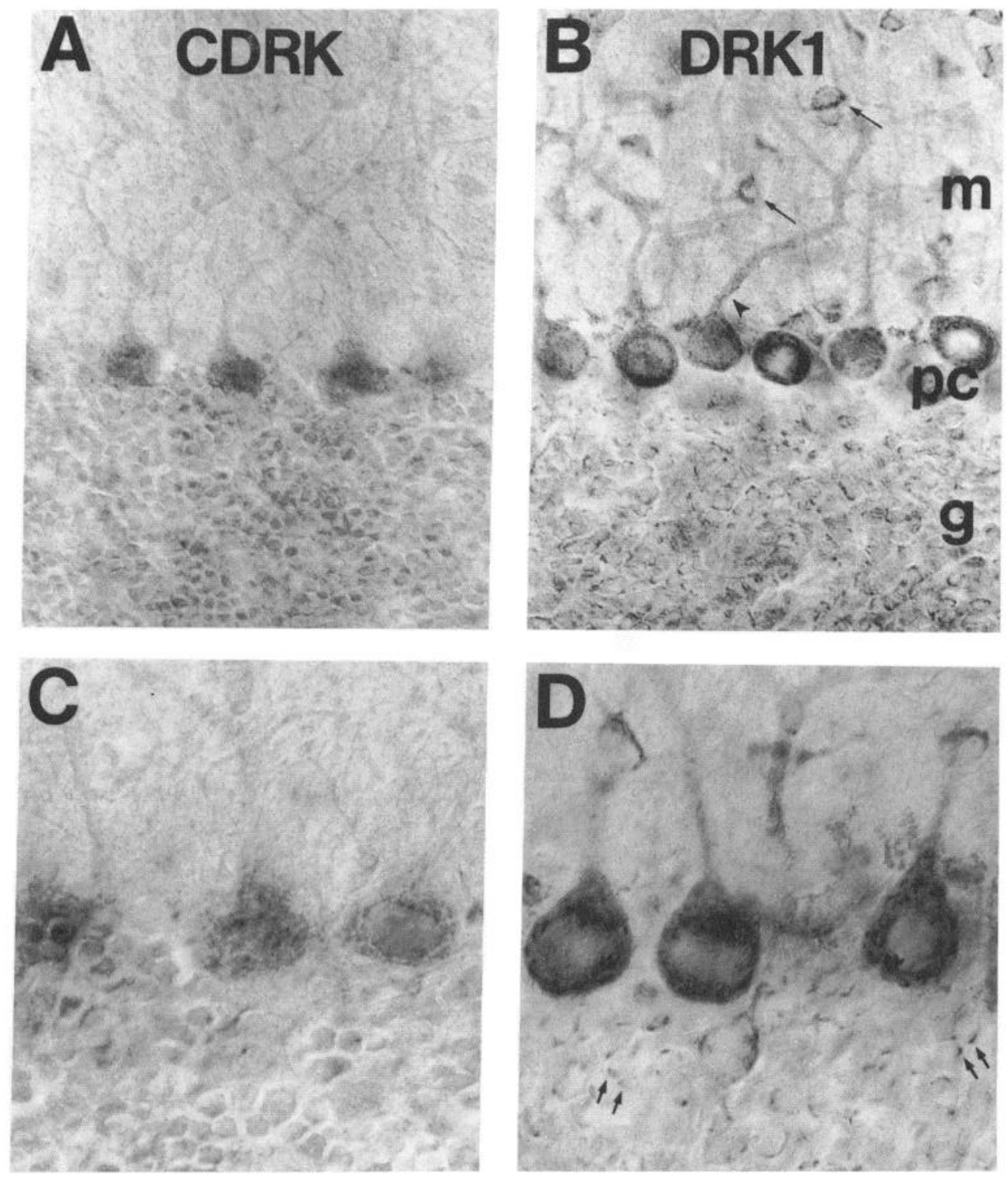

Figure 6. Cellular localizations of CDRK and DRK1 in the cerebellum. The bright-field photomicrographs of $\operatorname{CDRK}(A, 400 \times ; C, 630 \times)$ and DRK1 $(B, 400 \times ; D, 630 \times)$ show immunoreactivity in the molecular layer $(m)$, Purkinje cells $(p c)$, and granule cell layer $(g)$. CDRK is diffusely localized to the somata of both granule cells and Purkinje cells and faintly over the Purkinje cell main dendritic processes $(A$, $C)$. In contrast, the DRK1 pattern of immunoreactivity is highly distinctive with dense accumulations within the Purkinje cell body and proximal dendrites $(B$, arrowhead $)$. In the molecular layer, DRK1 also labels smaller cellular elements, consistent with stellate cells (B, small arrows) and basket cells. In the granule cell layer, dense accumulations of immunoreactivity are present in association with the surface region of granule cells, consistent with immunoreactivity of the perikaryal-dendritic region of the cell. This is clearly seen at higher power $(D$, arrows).

\section{Discussion}

The principal finding of our study is the striking difference in localization of CDRK and DRK1 channel proteins. Both channels are present predominantly in neurons, as previously observed for DRK1 by Trimmer (1991), who in preliminary studies observed staining in pyramidal cells in rat cerebral cortex.

Both CDRK and DRK1 display regional variations with overall levels of expression in the various brain regions being similar for the two channels. However, the cellular disposition of the two channels differs notably. The differences between the two channels are particularly striking in the cerebral cortex, where DRK1 immunoreactivity is largely restricted to pyramidal cells and their dendritic processes. CDRK is not evident at all in pyramidal cells but occurs in smaller, nonpyramidal cells resembling cortical interneurons. CDRK immunoreactivity is also extensive in processes of these cells, which at low magnification give a more diffuse appearance than the punctate staining of DRK1 in pyramidal cells.

The hippocampus provides another instance in which CDRK immunoreactivity predominates on neuronal processes. The molecular layer of the dentate gyrus is greatly enriched in CDRK but not in DRK1 immunoreactivity. This layer predominantly contains fibers of the perforant pathway arising from cell bodies in the entorhinal cortex.

The cerebellum clearly demonstrates the coexpression of CDRK and DRK1 in both Purkinje and granule cells. However, they have distinctly different patterns of localizations at the subcellular level. DRK1 is localized to the somata and proximal dendrites, while CDRK is associated more diffusely with the cell body.

What might be the differential functions of CDRK and DRK1 in the light of their respective relative enrichments in neuropil and somata? In cell bodies, delayed-rectifier $\mathrm{K}^{+}$channels play major roles in repolarizing neurons after action potentials as well as in setting and maintaining the resting membrane potential. In nerve terminals $\mathrm{K}^{+}$channels are involved in neurotransmitter release. Such considerations may relate to the differential functions of CDRK and DRK1. Conceivably, in Purkinje cells and granule cells of the cerebellum, CDRK may be playing a 
morc gencral role in cell function, whereas DRK1 may be subspecialized for dendrite-associated functions. Despite the large number of cloned $\mathrm{K}^{+}$channels, little is known of discrete functions for any of them, especially in mammalian systems. Our observations of differences in cellular disposition of CDRK and DRK 1 proteins may provide a model for exploring functions of other $\mathrm{K}^{+}$channels.

The marked differences in localizations of CDRK and DRK1 are somewhat surprising considering the similar amino acid sequence of the two. In the $\mathrm{N}$-terminal cytoplasmic domain the two channels display $86 \%$ amino acid identity, while in the transmembrane domain they display 95\% identity (Hwang et al., 1992). In the C-terminal cytoplasmic domain they show $63 \%$ identity. After the first 195 amino acids of the C-terminal cytoplasmic domain the two channels diverge with negligible homology, and CDRK is 51 amino acids shorter than DRK1. The extra 51 amino acids and the divergent amino acid sequences in DRK1 occur at the C-terminal region, which conceivably provides the targeting information that facilitates the different subcellular localizations of the two channels.

The observation of DRKl size heterogeneity is in striking contrast to CDRK, which migrates as a tight single band by Western analysis, suggesting that CDRK is not as extensively or heterogeneously modified posttranslationally. One possible explanation for this observation is that differential processing of CDRK and DRK1 is responsible for the differential cellular targeting of these two proteins. Alternatively, the differential modifications of CDRK and DRK1 may result from some intrinsic targeting information contained within the amino acid sequences of the two $\mathrm{K}^{+}$channels that directs them to the different subcellular compartments where they are then posttranslationally modified.

This immunolocalization study of CDRK and DRK1 provides insights allowing us to begin addressing the question of in vivo heteromeric $\mathrm{K}^{+}$channel complex formation. By in situ hybridization studies, we observe both CDRK and DRK1 mRNAs in the cell bodies of hippocampal dentate gyrus granule cells (Hwang et al., 1992). However, by immunohistochemistry we observe the two channel proteins predominantly localized either to granule cell bodies or to processes. Thus, in granule cells of the hippocampus these $\mathrm{K}^{+}$channels do not appear to form Shab subfamily member heteromers. On the other hand, we observe both CDRK and DRK1 proteins in cerebellar Purkinje cell somata, which may provide an opportunity for the formation of heteromers. Future studies using high-resolution immunohistochemical double-labeling techniques may definitively resolve the question of coexpression of $S h a b$ subfamily members within a single neuron.

\section{References}

Baldwin TJ, Tsaur M-L, Lopez GA, Jan YN, Jan LY (1991) Characterization of a mammalian cDNA for an inactivating voltage-sensitive $\mathrm{K}^{+}$channel. Neuron 7:471-483.
Baumann A, Grupe A, Ackermann A, Pongs O (1988) Structure of the voltage-dependent potassium channel is highly conserved from Drosophila to vertebrate central nervous systems. EMBO J 7:24572463.

Butler A, Wei A, Baker K, Lawrence S (1989) A family of putative potassium channel genes in Drosophila. Science 243:943-947.

Drewe JA, Verma S, Frech G, Joho RH (1992) Distinct spatial and temporal expression patterns of $\mathrm{K}^{+}$channel mRNAs from different subfamilies. J Neurosci 12:538-548.

Frech GC, VanDongen AMJ, Schuster G, Brown AM, Joho RH (1989) A novel potassium channel with delayed rectifier properties isolated from rat brain by expression cloning. Nature 340:642-645.

Harlow E, Lane D (1988) Antibodies: a laboratory manual. Cold Spring Harbor, NY: Cold Spring Harbor Laboratories.

Hwang PM, Glatt CE, Bredt DS, Yellen G, Snyder SH (1992) A novel $\mathrm{K}^{+}$channel with unique localizations in mammalian brain: molecular cloning and characterization. Neuron 8:473-481.

Laemmli UK (1970) Cleavage of structural proteins during assembly of the head of the bacteriophage T4. Nature 227:680-685.

McCormack T, De Miera V-S, Rudy B (1990) Molecular cloning of a member of a third class of Shaker-family $\mathrm{K}^{+}$channel genes in mammals. Proc Natl Acad Sci USA 87:5227-5231.

McKinnon D (1989) Isolation of a cDNA clone coding for a putative second potassium channel indicates the existence of a gene family. $J$ Biol Chem 264:8230-8236.

Pak MD, Baker K, Covarrubias M, Butler A, Ratcliffe A, Salkoff L (1991a) $\mathrm{mShal}$, a subfamily of A-type $\mathrm{K}^{+}$channel cloned from mammalian brain. Proc Natl Acad Sci USA 88:4386-4390.

Pak MD, Covarrubias M, Ratcliffe A, Salkoff L (1991b) A mouse brain homolog of the Drosophila Shab $\mathrm{K}^{+}$channel with conserved delayed-rectifier properties. J Neurosci 11:869-880.

Roberds SL, Tamkun MM (1991) Cloning and tissue-specific expression of five voltage-gated potassium channel cDNAs expressed in rat heart. Proc Natl Acad Sci USA 88:1798-1802.

Schwartz TL, Tempel BL, Papazian DM, Jan YN, Jan LY (1988) Multiple potassium-channel components are produced by alternative splicing at the Shaker locus in Drosophila. Nature 331:137-142.

Stühmer W, Ruppersberg JP, Schröter KH, Sakmann B, Stocker M, Giese KP, Perschke A, Baumann A, Pongs O (1989) Molecular basis of functional diversity of voltage-gated potassium channels in mammalian brain. EMBO J 8:3235-3244.

Takumi T, Ohkubo H, Nakanishi S (1988) Cloning of a membrane protcin that induccs a slow voltage-gated potassium current. Science 242:1042-1044.

Tempel BL, Papazian DM, Schwarz TL, Jan YN, Jan LY (1987) Sequence of a probable potassium channel component encoded at Shaker locus of Drosophila. Science 237:770-775.

Tempel BL, Jan NY, Jan LY (1988) Cloning of a probable potassium channel gene from mouse brain. Nature 332:837-839.

Towbin H, Staehelin T, Gorden J (1979) Electrophoretic transfer of proteins from polyacrylamide gels to nitrocellulose sheets: procedure and some applications. Proc Natl Acad Sci USA 76:4350-4354.

Trimmer JS (1991) Immunological identification and characterization of a delayed rectifier $\mathrm{K}^{+}$channel polypeptide in rat brain. Proc Natl Acad Sci USA 88:10764-10768.

Yokoyama S, Imoto K, Kawamura T, Higashida H, Iwabe N, Miyata T, Numa $S$ (1989) Potassium channels from NG108-15 neuroblastoma-glioma hybrid cells. FEBS LETT 259:37-42. 